DOI

\title{
МОЖЛИВОСТІ ВИКОРИСТАННЯ СТАНДАРТИЗОВАНОГО ОПИТУВАЛЬНИКА ДЛЯ ВИЗНАЧЕННЯ АВТОНОМНИХ ДИСФУНКЦІЙ В ОСІБ МОЛОДОГО ВІКУ
}

\author{
○Н. І. Шейко, В. п. Фекета
}

ДВНЗ «Ужгородський національний університет»

РЕЗЮМЕ. Синдром автономних дисфункцій-це поліетіологічний синдром, що характеризується дисфункцією автономної нервової системи і функціональними порушеннями всіх систем організму. Поширеність САД, за даними деяких авторів, складає від 20 до 56 \% всіх захворювань у осіб молодого віку, поступаючись лише ГРВІ.

Мета - виявити студентів з автономними дисфункціями та оцінити функціональний стан їх організму кількісно за допомогою показника активності регуляторних систем (ПАРС).

Матеріал і методи. До дослідження було залучено 100 студентів іноземців 2-3 курсів медичного факультету (1 група), та 100 студентів-українців молодших курсів інших факультетів (2 група) обох статей віком 17-23 роки. Для скринінгу автономних дисфункцій здійснювали анкетування за стандартним опитувальником А. М. Вейна. Для об'єктивноїхарактеристики функціонального стану автономної нервової системи використовували показники варіабельності серцевого ритму, отримані шляхом 5-хвилинної реєстрації ІІ відведення за допомогою комп'ютерного діагностичного комплексу «КардіоЛаб» («ХАІ-Медіка»,Україна). Зниження пристосувальних можливостей організму визначали за допомогою показника активності регуляторних систем (ПАРС).

Результати. За даними опитувальника А. М. Вейна, серед студентів-іноземців ознаки вегетативних змін мали 32 студенти (32\%), а серед українців-21 (21\%). Однак об'єктивно автономні дисфункції, підтверджені показниками варіабельності серцевого ритму, серед іноземців мали лише 18 осіб (18\%), а серед українців - 11 осіб (11\%) відповідно до загальної кількості опитаних студентів. Зокрема, 50 \% студентів-іноземців та 54,5 \% студентівукраїнців мали помірну функціональну напругу, тобто донозологічні стани, ПАРС 2-4; 22,2 \% студентів-іноземців та 27,3 \% студентів-українців мали виражену функціональну напругу, тобто преморбідний стан, ПАРС 5-6; 11,1 \% студентів-іноземців та 9,1 \% студентів-українців мали різко виражену функціональну напругу, стан незадовільної адаптації, ПАРС 7-8; 16,7 \% студентів-іноземців та 9,1 \% студентів-українців мали астенізацію (виснаження) регуляторних систем, ПАРС 9-10.

Висновки. Опитувальник А. М. Вейна може бути використаний для скринінгу синдрому автономних дисфункцій, однак необхідним є об'єктивне підтвердження за допомогою вимірювання показників варіабельності серцевого ритму.

КЛЮчОВІ СЛОВА: опитувальник Вейна; синдром автономних дисфункцій; показник активності регуляторних систем.

Вступ. Синдром автономних дисфункцій (САД) - це поліетіологічний синдром, що характеризується дисфункцією автономної нервової системи (АНC) і функціональними (тобто неорганічними) порушеннями з боку всіх систем організму [1]. Поширеність САД, за даними деяких авторів, складає від 20 до 56 \% всіх захворювань у осіб молодого віку, поступаючись лише ГРВІ. Причинами виникнення можуть бути спадкова схильність, ендокринні перебудови, стреси, неврози, надмірна фізична та розумова перевтома тощо [1-3]. Практично будь-який чинник, який за силою своєї дії перевищує функціональні можливості АНС, може сприяти виникненню синдрому автономних дисфункцій.

В основі автономних дисфункцій лежить пригнічення одного відділу за рахунок активності іншого. Однак у фізіологічних умовах при посиленні впливу в одному з відділів АНС у регуляторних механізмах іншого спостерігається компенсаторне напруження, тим самим система переходить на новий рівень функціонування, а відповідні гомеостатичні параметри відновлюються. У цих процесах важливе місце належить надсегментарним утворенням і сегментарним вегетативним рефлексам. Якщо організм перебуває в напруженому стані або в стані зриву адаптації, то порушується функція регулювання, посилюється активність одного з відділів, при цьому не виникає змін з боку іншого. А це і $\epsilon$ клінічний прояв симптомів автономних дисфункцій $[3,4]$.

Існує обґрунтована думка про те, що навчання в медичному вузі $\epsilon$ стресогенним для більшості студентів і небезпечним з точки зору ймовірності виникнення у них соматичної патології та синдрому автономних дисфункцій. Оскільки студенти-іноземці перебувають у чужій для них країні, рівень стресу зростає.

Мета - виявити студентів з автономними дисфункціями та оцінити функціональний стан їх організму кількісно за допомогою показника активності регуляторних систем (ПАРС).

Матеріал і методи дослідження. До дослідження було залучено 100 студентів іноземців 2-3 курсів медичного факультету (1 група), та 100 студентів-українців молодших курсів інших фа- 
Огляди літератури, оригінальні дослідження, погляд на проблему, випадок з практики, короткі повідомлення культетів (2 група) обох статей віком 17-23 роки. Усі вони не скаржилися на стан здоров'я і професійно не займалися спортом. Статистичної різниці між групами не було.

Для скринінгу автономних дисфункцій проводили анкетування за стандартним опитувальником А. М. Вейна. Для об'єктивної характеристики функціонального стану АНС використовували показники варіабельності серцевого ритму (ВСР), отримані шляхом 5-хвилинної реєстрації II відведення ЕКГ згідно з рекомендаціями Європейської та Північноамериканської асоціації кардіологів [1996] за допомогою комп'ютерного діагностичного комплексу «КардіоЛаб» («ХАІ-Медіка», Україна). Зокрема, визначали такі спектральні параметри BCP, як TP (Mc²) - загальна енергія спектра частот серцевого ритму, що відображає сумарний вплив на серцевий ритм всіх регуляторних систем; HF (мс²) - високочастотний компонент спектра серцевого ритму в діапазоні 0,15-0,4 Гц, що відображає переважно вагусний вплив на ритм серця, пов'язаний із диханням; LF $\left(\right.$ м $\left.^{2}\right)$ - низькочастотний компонент спектра серцевого ритму в діапазоні 0,04-0,15 Гц, що відображає переважно вплив симпатичного відділу AНС на серцевий ритм, в тому числі - активність судинно-рухового центру та $\operatorname{VLF}\left(\mathrm{MC}^{2}\right)$ - наднизькочастотний компонент спектра серцевого ритму в діапазоні 0,003-0,04 Гц, що відображає сумарну активність надсегментарних відділів АНС і нейрогуморальні впливи на ритм серця. Окрім цього, розраховували показник симпато-вагального балансу (LF/HF) та відсотковий внесок кож-

ного із частотних компонентів спектра В ТР (HF \%,LF \% та VLF \%) [5-7].

Зниження пристосувальних можливостей організму визначали за допомогою показника активності регуляторних систем (ПАРС). Запропонований ще на початку 80-х років минулого сторіччя інтегральний критерій ПАРС зарекомендував себе як ефективний в оцінці адаптаційних можливостей організму та дав змогу диференціювати різні ступені напруження регуляторних систем. Значення ПАРС виражають у балах від 1 до 10 [8].

При проведенні комплексних біологічних обстежень було дотримано засад Гельсінської декларації Всесвітньої медичної асоціації щодо етичних принципів медичних досліджень за участі людини в якості об'єкта досліджень. Аналіз і обробка результатів обстеження хворих здійснена за допомогою комп'ютерної програми STATISTICA 6.0 (фірми StatSoftInc, США).

Результати й обговорення. За даними опитувальника А. М. Вейна, ознаки вегетативних змін серед студентів-іноземців мали 32 студенти (32 \%) (результат за опитувальником від 16 до 49 балів при нормі $\leq 15)$, а серед українців - 21 (21\%). Однак о6'єктивно наявність автономних дисфункцій, підтверджених показниками варіабельності серцевого ритму, серед іноземців мали лише 18 осіб - $18 \%$ відповідно до загальної кількості опитаних студентів а6о 56,25 \% відповідно до даних опитувальника. Серед студентів-українців цей показник склав 11 студентів, тобто 11 \% відповідно до загальної кількості опитаних студентів або ж 52,38 \% відповідно до даних опитувальника (рис. 1).

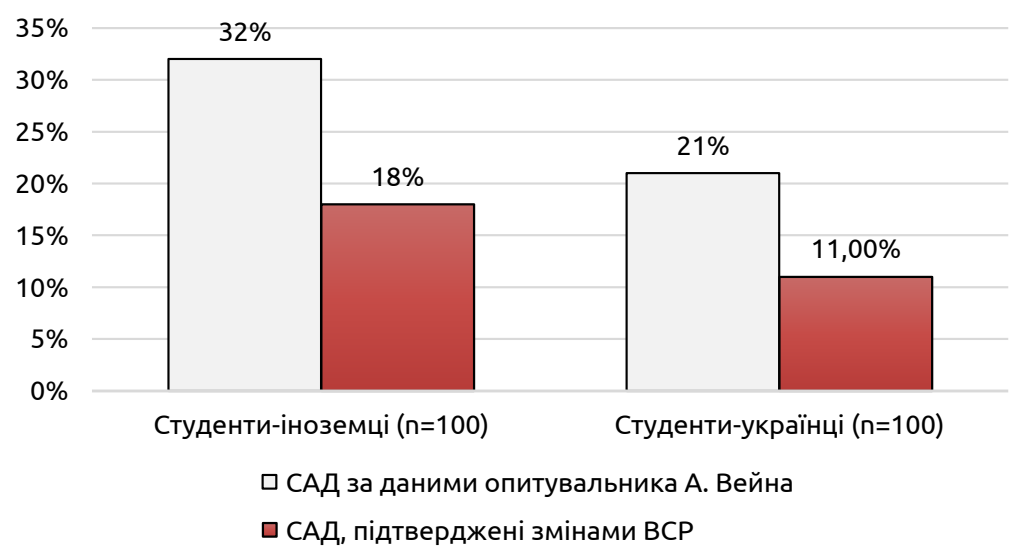

Рис. 1. Синдром автономних дисфункцій, виявлений серед досліджуваних груп.

Серед студентів з об'єктивно підтвердженими автономними дисфункціями за даними ВСР було проведено оцінку показника активності регуляторних систем (ПАРС), запропонованого Р. М. Баєвським та ін. у 1984 році (рис. 2): 50 \% студентів-іноземців та 54,5 \% студентів-українців мали помірну функціональну напругу, тобто донозологічні стани, при яких функції організму реалізуються більш високим, ніж у нормі, напруженням регуляторних систем, та виникають внаслідок високої активності людини або в кінці робочого дня. ПАРС 2-4; 22,2 \% студентів-іноземців та 
Огляди літератури, оригінальні дослідження, погляд на проблему, випадок з практики, короткі повідомлення 27,3 \% студентів-українців мали виражену функціональну напругу, тобто преморбідний стан, що характеризується зниженням функціональних резервів системи кровообігу та незадовільною адаптацією організму до умов навколишнього середовища. Наявність цього стану в спокої свідчить про неадекватну відповідь організму на чинники навколишнього середовища, а наявність постійного стресу призводить до прискореного використання життєвих ресурсів та виникнення захворювань. ПАРС 5-6; 11,1 \% студентів-іноземців та

9,1 \% студентів-українців мали різко виражену функціональну напругу, стан незадовільної адаптації з різким зниженням функціональних можливостей організму, що характеризується наявністю клінічних симптомів, виснаженням життєвих сил. ПАРС 7-8; 16,7 \% студентів-іноземців та 9,1 \% студентів-українців мали астенізацію (виснаження) регуляторних систем, тобто зрив адаптаційних процесів, нездатність організму підтримувати рівновагу з навколишнім середовищем. ПАРС 9-10.

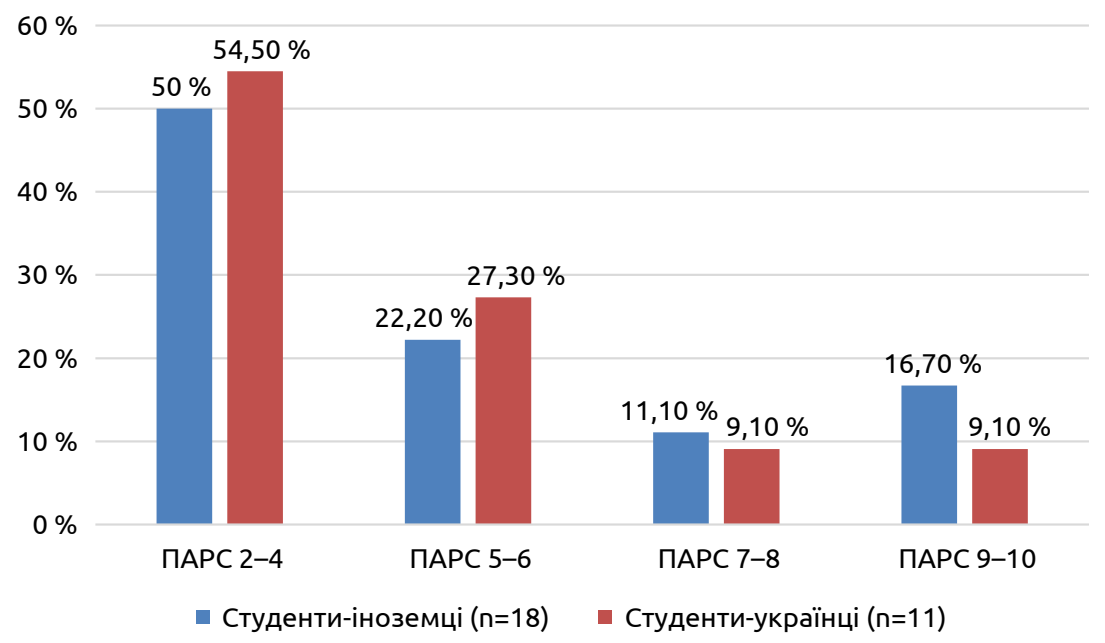

Рис. 2. Показник активності регуляторних систем серед досліджуваних груп.

Оскільки достовірної різниці між показниками ВСР в обох групах не було, в таблиці 1 ми навели середні значення показників обох груп. Як видно (табл. 1), середні значення показників варіабельності серцевого ритму в осіб з ПАРС 0-6 були в межах вікової норми. У осіб з ПАРС 7-8 вони прогресивно зростали, а у осіб з ПАРС 9-10 достовірно знижувались $(p<0,05)$, що свідчить про значне і тривале напруження i, як наслідок, виснаження організму та потребу в пошуку способів корекції вказаного стану.

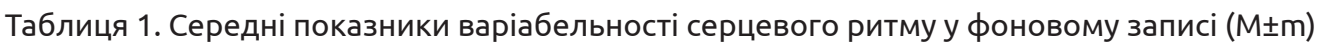

\begin{tabular}{|c|c|c|c|c|c|c|c|c|c|}
\hline ПАРС & $\begin{array}{c}\text { Кількість } \\
\text { студентів }\end{array}$ & $\begin{array}{c}\text { TP } \\
\left(\text { мс }^{2}\right)\end{array}$ & $\begin{array}{c}\text { VLF } \\
\left(\mathrm{MC}^{2}\right)\end{array}$ & $\begin{array}{c}\mathrm{LF} \\
\left(\mathrm{MC}^{2}\right)\end{array}$ & $\begin{array}{c}\mathrm{HF} \\
\left(\mathrm{MC}^{2}\right)\end{array}$ & $\begin{array}{c}\text { VLF } \\
\%\end{array}$ & $\begin{array}{c}\text { LF } \\
\%\end{array}$ & $\begin{array}{c}\text { HF } \\
\%\end{array}$ & LF\HF \\
\hline $0-1$ & 24 & $3589 \pm 217$ & $1402 \pm 309$ & $1169 \pm 393$ & $1018 \pm 413$ & $39,1 \pm 11,8$ & $32,6 \pm 10,0$ & $28,3 \pm 13,7$ & $1,91 \pm 1,7$ \\
\hline $2-4$ & 15 & $3782 \pm 232$ & $1121 \pm 127$ & $1548 \pm 139$ & $1113 \pm 439$ & $29,6 \pm 9,6$ & $40,9 \pm 16,4$ & $29,7 \pm 12,4$ & $1,44 \pm 0,81$ \\
\hline $5-6$ & 7 & $3287 \pm 373$ & $1331 \pm 158$ & $984 \pm 471$ & $972 \pm 108$ & $40,5 \pm 6,2$ & $29,9 \pm 6,6$ & $29,6 \pm 10,0$ & $1,2 \pm 0,55$ \\
\hline $7-8$ & 3 & $6219 \pm 708$ & $2949 \pm 353$ & $1696 \pm 197$ & $1574 \pm 154$ & $47,4 \pm 7,1$ & $27,2 \pm 1,4$ & $25,3 \pm 8,4$ & $0,97 \pm 0,32$ \\
\hline $9-10$ & 4 & $575 \pm 117^{*}$ & $292 \pm 124^{*}$ & $198 \pm 48^{*}$ & $85 \pm 33^{*}$ & $50,8 \pm 13,3$ & $34,4 \pm 16,2$ & $14,7 \pm 4,7$ & $3,42 \pm 1,9 *$ \\
\hline
\end{tabular}

Примітка. * p<0,05 відповідно до осіб з ПАРС 0-1 (показники ВСР в межах вікової норми).

Висновки. 1. Автономні дисфункції є поліетіологічним синдромом та досить часто трапляються в осіб молодого віку.

2. Опитувальник А. М. Вейна може бути використаним для скринінгу САД, однак необхідне об'єктивне підтвердження за допомогою вимірювання показників ВСР.
3. Більше поширення автономних дисфункцій серед студентів-іноземців можна пояснити їх перебуванням у більш стресових умовах через проживання в іншій країні, низький рівень знання української мови тощо.

4. Показники ВСР у осіб з ПАРС 9-10 (астенізація регуляторних систем) достовірно знижува- 
Огляди літератури, оригінальні дослідження, погляд на проблему, випадок з практики, короткі повідомлення лись, порівняно з аналогічними показниками у осіб з ПАРС 0-1 (норма).

Перспективи подальших досліджень. Планується здійснити пошук неінвазивних методів впливу на функціональний стан автономної нервової системи з метою корекції дисфункцій та нормалізації стану регуляторних систем.

\title{
ЛІТЕРАТУРА
}

1. Вейн А. М. Вегетативные расстройства: клиника, диагностика, лечение / под ред. А. М. Вейна. - М. : ООО «Медицинское информационное агентство», 2003. 752 c.

2. Вегетативні дисфункції у дітей / В. Г. Майданник, О. І. Сміян [та ін.]. - Суми : Сумський державний університет, 2014. - 186 c.

3. Скиба О. О. Патогенетичні особливості формування вегетативних дисфункцій у підлітків залежно від їх морфологічного статусу / О. О. Скиба // Вісник Дніпропетровського університету. Біологія, медицина. - 2017. № 1 (8).

4. Respiratory sinus arrhythmia as a non-invasive index of 'brain-heart' interaction in stress / I. Tonhajzerova, M. Mestanik // Indian J. Med. Res. - 2016. - No. 144 (6). P. 815-822.

\section{REFERENCES}

1. Veyn, A.M. (Ed.). (2003). Vegetativnye rasstroystva: Klinika, diagnostika, lechenye [Vegetative disorders: clinic, diagnosis, treatment]. Moscow: Meditsynskoe informatsyonnoye agentstvo [in Russian].

2. Maidannyk, V.H., \& Smiian, O.I. (2014). Vehetatyvni dysfunktsii u ditei [Vegetative dysfunctions in children]. Sumy: Sumy State University [in Russian].

3. Skyba, O.O. Patohenetychni osoblyvosti formuvannia vehetatyvnykh dysfunktsii u pidlitkiv zalezhno vid yikh morfolohichnoho statusu [Pathogenetic features of formation of autonomic dysfunctions in adolescents depending on their morphological status]. Visnyk Dnipropetrovskoho universytetu. Biolohiia, medytsyna - Bulletin of Dnipropetrovsk University. Biology. Medicine, 1 (8) [in Ukrainian].

4. Tonhajzerova, I., \& Mestanik, M. (2016). Respiratory sinus arrhythmia as a non-invasive index of 'brain-heart' interaction in stress. Indian J. Med. Res., 144 (6), 815-822.

5. Low A. Heart rate variability: New perspectives on assessment of stress and health risk at the workplace/ A. Low, R. McCraty // Heart Mind. - 2018. - No. 2. - P. 16-27.

6. Nikhil S. Heart rate variability: An old metric with new meaning in the era of using MHealth technologies for health and exercise training guidance / S. Nikhil, J. M. Kegan // Arrhythmia \& Electrophysiology Review. - 2018. No. 7 (4). - P. 247-255.

7. КардіоЛаб ВСР : методичні рекомендації по аналізу варіабельності серцевого ритму / Національний аерокосмічний університет "XAІ» НТЦ радіоелектронних медичних приладів і технологій XAI-Медіка. -X., 2009. - 66 с.

8. Леженко Г. О. Вегетативні дисфункції у дітей. Патогенез, діагностика і терапевтична тактика / Г. О. Леженко, О. Є. Пашкова // Дитячий лікар. - 2011. - № (11). C. 20-32.

5. Low, A., \& McCraty, R. (2018). Heart rate variability: New perspectives on assessment of stress and health risk at the workplace. Heart Mind, 2, 16-27.

6. Nikhil, S., \& Kegan, J.M. (2018). Heart rate variability: An old metric with new meaning in the era of using MHealth technologies for health and Exercise training guidance. Arrhythmia \& Electrophysiology Review, 7 (4), 247-255.

7. (2009). KardioLab VSR Metodychni rekomendatsii po analizu variabelnosti sertsevoho rytmu [CardioLab Methodical recommendations for analysis of cardiac rhythm variability]. National Aerospace University "KhAl" Scientific and technological center of electronic medical devices and technologies KhAl-Medika [in Ukrainian].

8. Lezhenko, H.O. (2011). Vehetatyvni dysfunktsii u ditei. Patohenez, diahnostyka i terapevtychna taktyka [Vegetative dysfunctions in children. Pathogenesis, diagnostics and therapeutic tactics]. Dytiachyi likar-Children's Doctor, 4 (11), 20-32 [in Ukrainian].

\section{ВОЗМОЖНОСТИ ИСПОЛЬЗОВАНИЯ СТАНДАРТИЗИРОВАННЫХ ОПРОСНИКОВ ДЛЯ ОПРЕДЕЛЕНИЯ АВТОНОМНЫХ ДИСФУНКЦИЙ У ЛИЦ МОЛОДОГО ВОЗРАСТА}

\author{
ГВУз «Ужгородский национальный университет»
}

РЕЗЮМЕ. Синдром автономных дисфункций - это полиэтиологический синдром, характеризующийся дисфункцией вегетативной нервной системы и функциональными нарушениями со стороны всех систем организма. Распространенность САД, по данным некоторых авторов, составляет от 20 до 56 \% всех заболеваний у лиц молодого возраста, уступая лишь ОРВИ.

Цель - выявить студентов с автономными дисфункциями и оценить функциональное состояние их организма количественно с помощью показателя активности регуляторных систем (ПАРС). 
Огляди літератури, оригінальні дослідження, погляд на проблему, випадок з практики, короткі повідомлення

Материал и методы. Кисследованию было привлечено 100 иностранных студентов 2-3 курсов медицинского факультета (1 группа) и 100 студентов-украинцев младших курсов других факультетов (2 группа) обоих полов в возрасте 17-23 года. Для скрининга автономных дисфункций осуществляли анкетирование по стандартному опроснику А. М. Вейна. Для объективной характеристики функционального состояния автономной нервной системы использовали показатели вариабельности сердечного ритма, полученные путем 5-минутной регистрации II отведения с помощью компьютерного диагностического комплекса «КардиоЛаб» («ХАИ-Медика», Украина). Снижение приспособительных возможностей организма определяли с помощью показателя активности регуляторных систем (ПАРС).

Результаты. По данным опросника А. М. Вейна, среди студентов-иностранцев признаки вегетативных изменений имели 32 студента (32 \%), а среди украинцев- 21 (21\%). Однако объективно наличие автономных дисфункций, подтвержденных показателями вариабельности сердечного ритма, среди иностранцев имели лишь 18 человек (18\%), а среди украинцев - 11 человек (11\%) соответственно от общего количества опрошенных студентов. В частности, 50 \% студентов-иностранцев и 54,5 \% студентов-украинцев имели умеренное функциональное напряжение, то есть донозологические состояния, ПАРС 2-4; 22,2 \% студентов-иностранцев и 27,3 \% студентов-украинцев имели выраженное функциональное напряжение, то есть преморбидное состояние, ПАРС 5-6; 11,1 \% студентов-иностранцев и 9,1 \% студентов-украинцев имели резко выраженное функциональное напряжение, состояние неудовлетворительной адаптации, ПАРС 7-8; 16,7 \% студентов-иностранцев и 9,1 \% студентов-украинцев имели астенизацию (истощение) регуляторных систем, ПАРС 9-10.

Выводы. Опросник А. М. Вейна может быть использован для скрининга синдрома автономных дисфункций, однако необходимо объективное подтверждение с помощью измерения показателей вариабельности сердечного ритма.

КЛЮЧЕВЫЕ СЛОВА: опросник Вейна; синдром аВтономнЫХ дисфУнкций; показатель активности регуляторных систем.

\section{POSSIBILITIES OF USING A STANDARDIZED EXAMINER FOR THE DETERMINATION OF AUTOMATIC DYSFUNCTIONS IN THE YOUNG AGE}

\section{Uzhhorod National University}

@N. I. Sheiko, V. P. Feketa

SUMMARY. The syndrome of autonomous dysfunctions (SAD) is a polyethiologic syndrome characterized by a dysfunction of the autonomic nervous system and functional disorders from all systems of the body. The prevalence of SAD, according to some authors, is from 20 to $56 \%$ of all diseases in young people, inferior to only ARVI.

The aim - to identify students with autonomic dysfunctions and evaluate their functional status quantitatively by using the indicator of the activity of regulatory systems (IARS).

Material and Methods. The study involved 100 international students from the $2 \mathrm{nd}-3 \mathrm{rd}$ year of students of the medical faculty (group 1), and 100 Ukrainian students of junior high schools of other faculties (group 2) of both sexes aged 17-23. For the screening of autonomic dysfunctions questionnaires were performed on the standard questionnaire by A. M. Vein. For the objective characterization of the functional state of the autonomic nervous system, indicators of heart rate variability were obtained using the 5-minute second registration with the computer diagnostic complex "CardioLab" ("KhAl-Medika", Ukraine). Reducing the adaptive capacity of the body was determined by using the indicator of the activity of regulatory systems (IARS).

Results. According to the questionnaire by A. M. Vein autonomic dysfunctions were found in 32 foreign students or $32 \%$, and 21 or $21 \%$ among Ukrainians. However, objectively the presence of autonomic dysfunctions confirmed by indicators of heart rate variability among foreigners was only 18 persons - $18 \%$, and among Ukrainians - 11 students, that is $11 \%$ according to the total number of students polled. In particular, $50 \%$ of foreign students and $54.5 \%$ of Ukrainian students had moderate functional tension, that is prenosological conditions, IARS $2-4 ; 22.2 \%$ of foreign students and $27.3 \%$ of Ukrainian students had a pronounced functional tension, that is premorbid condition, IARS 5-6; $11.1 \%$ of foreign students and $9.1 \%$ of Ukrainian students had a pronounced functional stress, poor adaptation status, and IARS $7-8 ; 16.7 \%$ of foreign students and $9.1 \%$ of Ukrainian students had an underestimate (depletion) of regulatory systems, IARS 9-10.

Conclusions. The questionnaire by A. M. Vein can be used for the screening of autonomic dysfunctions syndrome, but objective confirmation is required by measuring the heart rate variability.

KEY WORDS: vein questionnaire; autonomic dysfunction syndrome; index of activity of regulatory system. 